\title{
Real-Life Experience with Selexipag as an Add-On Therapy to Oral Combination Therapy in Patients with Pulmonary Arterial or Distal Chronic Thromboembolic Pulmonary Hypertension: A Retrospective Analysis
}

\author{
Berlier, Charlotte ; Schwarz, Esther I ; Saxer, Stéphanie ; Lichtblau, Mona ; Ulrich, Silvia
}

\begin{abstract}
BACKGROUND: Patients with pulmonary arterial hypertension (PAH) and distal chronic thromboembolic pulmonary hypertension $(\mathrm{CTEPH})$ who still reveal risk factors of worse prognosis on double combination therapy may benefit from add-on therapy with the novel oral selective prostacyclin receptor agonist selexipag. METHODS: We reviewed all patients with PAH/distal CTEPH in the Zurich cohort who received selexipag as add-on to oral combination therapy and retrieved New York Heart Association (NYHA) functional class, 6-min walk distance (6MWD), NT-pro-BNP, quality of life questionnaires (CAMPHOR and EuroQoL), tricuspid pressure gradient (TPG) by echocardiography and cardiopulmonary exercise test parameters (power output and oxygen uptake). RESULTS: Twenty-three patients with PAH/CTEPH (20/3), 14 females, median (quartiles) age 56 (46; 66) years received an oral triple therapy containing selexipag at a median dose of 2000 (1600; 3100) mcg during 221 (113; $359)$ days. The following parameters were stabilized from baseline to last FU: 6MWD (440 (420; 490) to $464(420 ; 526) \mathrm{m})$, NYHA class (three to two), NT-pro-BNP $(326(167 ; 1725)$ to $568(135 ; 1856)$ ng/l), TPG, power output, and oxygen uptake. Quality of life reflected by the CAMPHOR and EuroQoL improved. CONCLUSIONS: Early initiation of triple oral combination therapy including selexipag in $\mathrm{PAH} / \mathrm{CTEPH}$ with intermediate risk factor profile may help to stabilize functional class, exercise performance, and pulmonary hemodynamics in a real-life setting and potentially improves quality of life. Whether these beneficial effects can be truly attributed to the addition of selexipag should be addressed in future randomized controlled trials.
\end{abstract}

DOI: https://doi.org/10.1007/s00408-019-00222-7

Posted at the Zurich Open Repository and Archive, University of Zurich

ZORA URL: https://doi.org/10.5167/uzh-179407

Journal Article

Accepted Version

Originally published at:

Berlier, Charlotte; Schwarz, Esther I; Saxer, Stéphanie; Lichtblau, Mona; Ulrich, Silvia (2019). Real-Life Experience with Selexipag as an Add-On Therapy to Oral Combination Therapy in Patients with Pulmonary Arterial or Distal Chronic Thromboembolic Pulmonary Hypertension: A Retrospective Analysis. Lung, 197(3):353-360.

DOI: https://doi.org/10.1007/s00408-019-00222-7 


\title{
Real-life experience with selexipag as an add-on therapy to oral combination therapy in patients with pulmonary arterial or distal chronic thromboembolic pulmonary hypertension: a retrospective analysis
}

Charlotte Berlier, Esther I. Schwarz, Stéphanie Saxer, Mona Lichtblau, Silvia Ulrich

Clinic of Pulmonology, University Hospital of Zurich, Zurich, Switzerland

Short-title: Oral triple therapy in PAH and CTEPH

\author{
Corresponding author \\ Prof. Dr. med. Silvia Ulrich \\ Clinic of Pulmonology \\ University of Zurich \\ Raemistrasse 100, 8091 Zurich, Switzerland \\ Phone: +41/44 25543 62; Fax: +41/442558517 \\ E-mail: silvia.ulrich@usz.ch
}

Key words: pulmonary hypertension, pulmonary arterial hypertension, vasodilator therapy, endothelin-receptor antagonist, phosphodiesterase-inhibitor, selexipag, chronic thromboembolic pulmonary hypertension

Word count: body of manuscript: 2446 words, abstract: 213 words.

3 tables, 2 figures. 


\section{ABSTRACT}

Purpose: Patients with pulmonary arterial hypertension (PAH) and distal chronic thromboembolic pulmonary hypertension (CTEPH) who still reveal risk factors of worse prognosis on double combination therapy may benefit from add-on therapy with the novel oral selective prostacyclin-receptor agonist selexipag.

Methods: We reviewed all patients with PAH/distal CTEPH in the Zurich cohort who received selexipag as add-on to oral combination therapy and retrieved New York Heart Association (NYHA) functional class, 6 minute walk distance (6MWD), NT-pro-BNP, quality of life questionnaires (CAMPHOR and EuroQoL), tricuspid pressure gradient (TPG) by echocardiography and cardiopulmonary exercise test parameters (power output and oxygen uptake).

Results: 23 patients with PAH/CTEPH (20/3), 14 females, median (quartiles) age $56(46 ; 66)$ years received an oral triple therapy containing selexipag at a median dose of 2000 (1600;3100) mcg during 221 (113;359) days. The following parameters stabilized from baseline to last FU: 6MWD $(440(420 ; 490)$ to $464(420 ; 526)$ meters), NYHA class (3 to 2), NT-pro-BNP (326 $(167 ; 1725)$ to $568(135 ; 1856)$ ng/l), TPG, power-output and oxygen uptake. Quality of life reflected by the CAMPHOR and EuroQoL improved.

Conclusions: Early initiation of triple oral combination therapy including selexipag in $\mathrm{PAH} / \mathrm{CTEPH}$ with intermediate risk factor profile may contribute to stabilize functional class, exercise performance and pulmonary hemodynamics in a real life setting and potentially improves quality of life. Whether these beneficial effects can be truly attributed to the addition of selexipag should be addressed in future randomized-controlled trials. 


\section{Introduction}

Precapillary pulmonary hypertension $(\mathrm{PH})$ is a serious condition leading to impaired exercise tolerance, quality of life and reduced life expectancy if untreated (1). In the absence of relevant lung or heart disease, the two major forms are pulmonary arterial and chronic thromboembolic pulmonary hypertension (PAH and CTEPH). Whereas symptoms in many patients with CTEPH can substantially improve with pulmonary endarterectomy or balloonpulmonary angioplasty, different medical therapies ameliorate symptoms, exercise capacity and quality of life in PAH and in persisting CTEPH after treatment or inoperable CTEPH, which share pathogenic features with $\mathrm{PAH}(1-5)$. $\mathrm{PH}$ is characterized by the vasoconstriction of pulmonary artery smooth muscles, vascular remodeling and endothelial cell proliferation (6). Three major involved pathogenic pathways are therapeutically addressed to date: the nitric oxide, endothelin and prostacyclin pathways.

Oral drugs targeting the endothelin and nitric oxide pathways are commonly initiated in ambulatory patients, whereas initial intravenous prostanoid are used in patients presenting with advanced disease stages in right heart failure (1). Recent randomized controlled trials like the AMBITION (7), PATENT PLUS (8) and SERAPHIN trial (9) have shown that initial early combination therapy addressing both the endothelin- and nitric oxide pathways have higher efficacy in improving symptoms, clinical worsening and exercise capacity in PAH, and thus current recommendations support the early use of combination therapy, which is widespread initiated as initial oral combination therapy $(1,7,9-12)$. Initial use of triple combination therapy addressing all available pathways was mainly reserved for severe cases in NYHA functional class IV due to the need of an indwelling catheter for continuous prostanoid therapy. Selexipag is an oral highly selective prostacyclin receptor agonist and has been approved by the FDA in December 2015 allowing an oral combination therapy targeting the prostacyclin pathway. In a placebo-controlled phase 2 study with PAH-patients receiving single or double therapy, addition of selexipag significantly reduced the pulmonary vascular resistance (PVR) by $30.3 \%$ after 17 weeks of treatment (13). In a large randomized placebo-controlled phase 3 study (GRIPHON) including PAH patients on oral mono or dual therapy for $\mathrm{PAH}$, selexipag reduced the primary composite end point of death or a complication related to $\mathrm{PAH}$ by $40 \%$ (hazard ratio in the selexipag group as compared with the placebo group 0.6, $p<0.001)$ )(14). This treatment effect was driven by differences in disease progression and hospitalization as there was no significant difference in mortality between the two study groups as disease progression was a predefined endpoint and terminated the study for the patient in investigation (14). Subgroup analysis in PAH associated with connective tissue disease (CTD) revealed similar improvements of the same primary composite endpoint (15). The role of combination therapy in distal inoperable or postoperative persisting CTEPH is less clear. However, many experts agree that distal 
CTEPH is medically treated in analogy to $\mathrm{PAH}$ as both share similar pathogenic features $(5$, $10,16,17)$.

Early combination therapy is commonly used in clinical practice $(10,16)$ and since the availability of selexipag in Switzerland, triple oral combination therapy including selexipag is commonly offered to patients not fulfilling all criteria of favorable prognosis. There are currently very scarcely data available on the clinical course of patients with PAH or CTEPH receiving selexipag in real life conditions. We therefore analyzed all patients in the Zurich $\mathrm{PH}$ cohort who received triple therapy with selexipag.

\section{Methods}

This retrospective cohort study complied with the ethical laws in Switzerland and all patients have signed informed consent for the Zurich PH cohort study (KEK 2014-0214).

\section{Study design and patients}

This is a retrospective analysis of data from all adults (>18y) with PAH or distal CTEPH in whom selexipag was initiated at the University Hospital Zurich between July 2016 and April 2018 due to not fulfilling all criteria for favorable prognosis according to the latest guidelines (1). The data from the last visit before starting selexipag were considered as baseline. Right heart catheterization $(\mathrm{RHC})$ data of the last $\mathrm{RHC}$ available before the start of selexipag was retrieved. Variables assessed at baseline, at 2-4 months follow-up (FU) and at the last visit or at the last visit before stopping selexipag included the NYHA class, the six minute walk distance (6MWD), the N-terminal pro brain natriuretic peptide (NT-proBNP), echocardiographic assessments of the tricuspid pressure gradient (TPG), as surrogate for pulmonary artery pressure, the tricuspid annual plane systolic excursion (TAPSE) and the systolic/diastolic fractional area change of the right ventricle (FAC\%) as markers of cardiac function (18), and also the maximal power output, oxygen uptake and VE/VCO2 slope retrieved from maximal ramp cycle cardiopulmonary exercise test (CPET). Quality of life questionnaires (Cambridge Pulmonary Hypertension Outcome Review (CAMPHOR), EuroQoL and Minnesota living with heart failure questionnaire (MLHF)) as well as patient self-reported therapeutic effect (I feel better, worse, equal) and self-reported health status (scaled from very bad, bad, not so good, good, very good and excellent) were retrieved at baseline and after on average 6 months of FU. We compared and statistically analyzed the variables between baseline and FU as well as between baseline and 'last visit'. The 'last visit' consisted in the last available visit or the last visit before stopping selexipag. In patients who stopped selexipag, the last visit was additionally analyzed separately. We used the risk 
stratification strategy of the last guidelines (1) to categorize patients as low, intermediate or high risk at baseline, following the validation strategy of Kylhammar et al (19).

\section{Treatment regimen}

All patients received an oral double therapy with endothelin receptor antagonist (ERA) and phosphodiesterase type 5 (PDE-5) inhibitors or soluble guanylate cyclase (sGC) stimulator. One patient on inhaled lloprost was switched to selexipag and one patient was pretreated also with imatinib since years. Selexipag treatment was initiated at a dose of $200 \mathrm{mcg}$ bid and increased weekly in increments of $200 \mathrm{mcg}$ bid until the maximal dose of $1600 \mathrm{mcg}$ bid was reached or until unmanageable adverse effects developed (headache, jaw pain, nausea or diarrhea). Specialized nurses controlled the up-titration with weekly telephone calls according to clinical practice.

\section{Statistical analysis}

Data were stored in the secure database of the Zurich PH cohort. Analysis was performed using the SPSS Statistics 25. All data are expressed as median (quartiles). Comparison of NYHA class, 6MWD, blood-, echocardiography- and CPET- parameters were performed using non-parametric Wilcoxon test due to non-normal distribution of the majority of data. A p-value $<0.05$ was considered statistically significant. We calculated the Cohen's effect size for quality of life parameters as the mean change during follow-up divided by the standard deviation at baseline for the quality of life questionnaires items. Due to the exploratory nature of our clinical study, we did not perform an a priori sample size calculation. However, we computed nonparametric $95 \%$ confidence intervals of changes in quality of life to assess the precision of these outcomes.

\section{Results}

\section{Baseline patient characteristics}

Baseline characteristics and therapy of 23 patients (14 females, median age 56 years) who had selexipag added to oral combination therapy are shown in table 1 and table 2 . There were only 3 patients with distal CTEPH in this observational study, two of them with persisting $\mathrm{PH}$ after pulmonary endarterectomy and one patient was inoperable. Functional class, 6MWD and echocardiography were available for all patients at baseline, CPET in 12 . CPET at baseline showed a reduced maximal oxygen uptake (peak $\mathrm{VO}_{2} \mathrm{max}$ ), a reduced power output and increased $\mathrm{VE} / \mathrm{VCO}_{2}$ slope. According to the risk classification proposed by Boucly et al $(1,20), 7$ patients were in the low risk, 15 in the intermediate risk and 1 patient in the high risk group, but all revealed at least one factor of worse prognosis. 


\section{Follow-up at 2-4 months}

Follow-up data at visit 2-4 months after start of selexipag was available in 20 patients (table 2 and figure 1), the daily selexipag dose achieved was 2200 (1600; 3200) mcg. The 6MWD improved significantly to $447(420 ; 507)$ meters $(+7 \mathrm{~m}, \mathrm{p}$ 0.035). The resting peripheral oxygen saturation $\left(\mathrm{SpO}_{2}\right)$ and the Borg scale at peak 6MWD improved significantly $\left(\mathrm{SpO}_{2}\right.$ from $96 \%(92 ; 97)$ to $97 \%(94 ; 98)$, p 0.043 , Borg from $5(4 ; 7)$ to $4(3 ; 5)$ points, p 0.009). The NYHA class and NT-pro-BNP remained stable. Individually analyzed, 12 patients remained in the same NYHA class, 5 patients improved, and 3 deteriorated. Follow-up echocardiographic and CPET-variables from 8 respectively 5 patients showed no difference compared to baseline.

\section{Last visit}

Data for the last visit was available from 22 patients, after $221(113 ; 359)$ days of observation (table 2 and figure 1). The 6MWD remained stable with $464(420 ; 526)$ meters in comparison with the baseline 6MWD. The $\mathrm{SpO}_{2}$ at rest and at peak exercise, the Borg scale and the NTpro-BNP remained stable. Even though the median pro-BNP doubled at the last visit in comparison with the baseline, this increase was not significant. Overall, there was no difference in the NYHA class from baseline to the last visit (median 3 vs. 2, p 0.14). Individually analyzed, 13 patients remained in the same NYHA class, 7 patients improved and 2 deteriorated (figure 2). The echocardiographic $(n=18)$ and the CPET $(n=13)$ variables remained stable. The daily selexipag dose achieved was 2000 (1600; 3100) mcg.

Quality of life

Quality of life questionnaires were available in half of the patients (table 3). There was a significant improvement in the symptoms and quality of life items of the CAMPHOR questionnaire, whereas the activity item remained stable. The effect size of the change of the CAMPHOR was between 0.4 to 0.8 . There was also a significant improvement in the EuroQoL visual analogue scale from 55 to 65 (a higher score meaning a better quality of life), with a good effect size of 0.8 . More patients rated themselves as better under additional selexipag therapy as showed in the patient self-reported therapeutic effect questionnaire and the self-reported health status stayed stable (a lower score indicating a better status), with a good effect size of 1.2 and 0.5 respectively. The MLHF questionnaire was low at baseline and remained stable under therapy (a lower score indicating a better quality of life).

Stop of selexipag

Six patients stopped selexipag during the observational period. Two patients (1 PAH, 1 CTEPH) were switched to intravenous prostacyclin after 345 respectively 111 days due to 
insufficient clinical stabilization and listing for lung transplantation. One patient with congenital heart disease stopped selexipag because of intense head- and muscle ache and worsening of $\mathrm{SpO}_{2}$. One PAH-patient stopped selexipag due to persistent diarrhea and pruritus and two because of lack of subjective benefit. The therapy duration for the patients who stopped selexipag was $218(111 ; 254)$ days and the selexipag dose $2400(1000 ; 3000)$ $\mathrm{mcg}$.

\section{Mortality and hospitalization}

One 73 years old patient died during the observational period due to a septic shock with staphylococcus aureus 283 days after the initiation of selexipag therapy. This death was not related to PAH and its therapy. One patient was hospitalized due to an influenza infection and one due to progressive right heart failure necessitating intravenous diuretic therapy.

\section{Discussion}

Our retrospective study describes for the first time the clinical outcome of patients with PAH or distal CTEPH treated with selexipag as add-on to oral combination therapy in a real-life setting. We found that triple oral combination therapy adding selexipag was generally well tolerated and may contributed to stabilize exercise capacity, NYHA class, NT-pro-BNP, pulmonary artery pressure and right heart function and available questionnaire assessment revealed improved quality of life scores and symptoms.

Initial combination therapy has been shown efficacy in randomized trials and delayed disease progression and its early initiation even in patients with more favorable risk factor profiles may be beneficial (1). According to recently published risk assessments strategies, 7 , 15 and 1 patients of the present collective would be assigned to low, intermediate and high risk (19-21). But even in the low risk group, the patients did not fulfil all beneficial criteria, which is why we proposed escalation of drug therapy.

The post-hoc analysis of the GRIPHON study (22) analyzed the subgroup of patients $(n=376)$ who received double oral therapy with ERAs and PDE-5 inhibitors before adding selexipag versus placebo. In this subgroup, selexipag reduced the composite end-point of death or a complication related to PAH by $37 \%$ compared to placebo, indicating a similar effect as in the overall GRIPHON population (14).

The 6MWD is one of the most widespread used prognostic marker and study endpoint, however, the observed changes are usually less in combination therapy trials (23). In our retrospective real life cohort after a median treatment time of 8 months, the median 6MWD increased by 24 meters, however, due to small number and variable response, this was not 
significant but relates to the treatment effect of 12 meters in GRIPHON (12). Exercise capacity assessed by CPET was also stabilized, reflected by a trend towards an improved peakVO $\mathrm{VE}_{2}, \mathrm{VE} / \mathrm{VCO}_{2}$ slope and power output. Improving CPET would be of high relevance for patients, as CPET parameters have a prognostic value predicting survival and time to clinical worsening (24). NYHA class remained stable in the majority of patients (13 patients), improved in 7 and deteriorated in 2 patients. Thus, the percentage of patients not revealing a worsening of the NYHA class in our cohort is slightly higher than in GRIPHON (91 vs. 78\%) and reassuring in a real-life setting. Echocardiographic assessment at the last visit showed that all assessed parameters remained stable on oral triple combination therapy and so did the NT-pro-BNP.

An improved quality of life is an important and patient-relevant outcome parameter, and the measurement of the quality of life endpoint enables to have a more comprehensive and relevant assessment of therapeutic effects. A better quality of life was furthermore predictive of the prognosis in PAH/CTEPH (4). The CAMPHOR was designed as a disease-specific score to assess symptoms, activity limitations and quality of life. It has a good internal consistency and reproducibility and its German version has also been validated $(25,26)$. The significant improvement in the symptoms and quality of life items of the CAMPHOR questionnaire with an effect size ranging from 0.4 to 0.8 depending on the items, which is concordant with the described ranges of the effect size in the literature and is clinically relevant (27). It is thus patient relevant and underscores the potential use of early initiated triple combination therapy. The fact that the item activity of the CAMPHOR questionnaire remained stable again points towards a stabilization on therapy and underscores the fact that further improvement in exercise capacity/activity might be difficult to achieve in pretreated patients. There was also a significant improvement in the EuroQoL visual analogue scale (similar to a thermometer), which is a standardized non-disease specific instrument for assessing quality of life (28). The MLHF questionnaire has been shown to be a significant predictor of outcome in a prospective study investigating the performance and clinical relevance of the MLHF in PAH and CTEPH patients (4). The patient self-reported therapeutic effect and health status showed also an amelioration and stabilization, here also with a high effect size of $\geq 0.5$.To our knowledge, this is the first report on quality of life measures on selexipag, showing an amelioration in two important disease-specific scores and parameters of global assessments.

Our study has several limitations. The major one is that this is a retrospective analysis in a relatively small number of patients, particularly the CTEPH group was very small and thus will not allow subgroup analysis concerning CTEPH alone. As we have no control group available, it remains speculative whether stabilization in this cohort was due to the addition of selexipag to the established double combination therapy and lead-time bias may apply. 
Although all patients had some factor of unfavorable prognosis, the majority was in an

intermediate-to low risk profile. The fact that two patients were switched to an intravenous prostanoid during the course of the analysis underscores the importance of close follow-up of this patients in a tertiary care center.

In conclusion, oral triple combination therapy by adding selexipag to an established double combination therapy may contributed to stabilization of the NYHA class, exercise capacity and hemodynamics, and improves quality of life in patients with PAH or distal CTEPH with risk parameters for unfavorable prognosis. Further randomized trials should assess the value of triple oral combination therapy in PAH or distal CTEPH not fulfilling all favorable risk criteria.

\section{Compliance with Ethical Standards:}

The study was funded by grants for the Zurich PH-cohort from the Zurich Lung.

Conflict of interest: None of the authors declares any conflict of interest in relation to the present work. SU received grant money from the Swiss National Science Foundation, Zurich Lung, Actelion SA, Bayer SA, Orpha Swiss. SU; EIS, SS, ML and CB received travel support and lecture fees from Actelion SA, Bayer SA, MSD SA and Orpha Swiss.

Ethical approval: All procedures performed in studies involving human participants were in accordance with the ethical standards of the institutional and/or national research committee and with the 1964 Helsinki declaration and its later amendments or comparable ethical standards. This retrospective cohort study complied with the ethical laws in Switzerland and all patients have signed informed consent for the Zurich PH cohort study (KEK 2014-0214).

\section{References}

1. Galie N, Humbert M, Vachiery JL, Gibbs S, Lang I, Torbicki A, et al. 2015 ESC/ERS Guidelines for the diagnosis and treatment of pulmonary hypertension: The Joint Task Force for the Diagnosis and Treatment of Pulmonary Hypertension of the European Society of Cardiology (ESC) and the European Respiratory Society (ERS): Endorsed by: Association for European Paediatric and 
Congenital Cardiology (AEPC), International Society for Heart and Lung Transplantation (ISHLT). Eur Respir J. 2015.

2. Wilkens H, Konstantinides S, Lang I, Bunck AC, Gerges M, Gerhardt F, et al. [Chronic thromboembolic pulmonary hypertension: Recommendations of the Cologne Consensus Conference 2016]. Dtsch Med Wochenschr. 2016;141(S 01):S62-S9.

3. Ulrich S, Fischler M, Speich R, Popov V, Maggiorini M. Chronic thromboembolic and pulmonary arterial hypertension share acute vasoreactivity properties. Chest. 2006;130(3):841-6.

4. Cenedese E, Speich R, Dorschner L, Ulrich S, Maggiorini M, Jenni R, et al. Measurement of quality of life in pulmonary hypertension and its significance. Eur Respir J. 2006;28(4):808-15.

5. Cannon JE, Pepke-Zaba J. Is distal chronic thromboembolic pulmonary hypertension treatable with PAH targeted drugs? Semin Respir Crit Care Med. 2013;34(5):620-6.

6. Voelkel NF, Cool C. Pathology of pulmonary hypertension. Cardiol Clin. 2004;22(3):343-51, v. 7. Galie N, Barbera JA, Frost AE, Ghofrani HA, Hoeper MM, McLaughlin VV, et al. Initial Use of Ambrisentan plus Tadalafil in Pulmonary Arterial Hypertension. N Engl J Med. 2015;373(9):834-44.

8. Galie N, Muller K, Scalise AV, Grunig E. PATENT PLUS: a blinded, randomised and extension study of riociguat plus sildenafil in pulmonary arterial hypertension. Eur Respir J. 2015;45(5):1314-22.

9. Pulido T, Adzerikho I, Channick RN, Delcroix M, Galie N, Ghofrani HA, et al. Macitentan and morbidity and mortality in pulmonary arterial hypertension. N Engl J Med. 2013;369(9):809-18.

10. Bartenstein P, Saxer S, Appenzeller P, Lichtblau M, Schwarz EI, Ulrich S. Risk Factor Profiles Achieved with Medical Therapy in Prevalent Patients with Pulmonary Arterial and Distal Chronic Thromboembolic Pulmonary Hypertension. Respiration. 2018.

11. Sitbon O, Sattler C, Bertoletti L, Savale L, Cottin V, Jais X, et al. Initial dual oral combination therapy in pulmonary arterial hypertension. Eur Respir J. 2016;47(6):1727-36.

12. Ghofrani HA, Galie N, Grimminger F, Grunig E, Humbert M, Jing ZC, et al. Riociguat for the treatment of pulmonary arterial hypertension. N Engl J Med. 2013;369(4):330-40.

13. Simonneau G, Torbicki A, Hoeper MM, Delcroix M, Karlocai K, Galie N, et al. Selexipag: an oral, selective prostacyclin receptor agonist for the treatment of pulmonary arterial hypertension. Eur Respir J. 2012;40(4):874-80.

14. Sitbon O, Channick R, Chin KM, Frey A, Gaine S, Galie N, et al. Selexipag for the Treatment of Pulmonary Arterial Hypertension. N Engl J Med. 2015;373(26):2522-33.

15. Gaine S, Chin K, Coghlan G, Channick R, Di Scala L, Galie N, et al. Selexipag for the treatment of connective tissue disease-associated pulmonary arterial hypertension. Eur Respir J. 2017;50(2).

16. Mueller-Mottet S, Stricker H, Domenighetti G, Azzola A, Geiser T, Schwerzmann M, et al. Long-term data from the Swiss pulmonary hypertension registry. Respiration. 2015;89(2):127-40. 17. Pepke-Zaba J, Delcroix M, Lang I, Mayer E, Jansa P, Ambroz D, et al. Chronic thromboembolic pulmonary hypertension (CTEPH): results from an international prospective registry. Circulation. 2011;124(18):1973-81.

18. Evangelista A, Flachskampf F, Lancellotti P, Badano L, Aguilar R, Monaghan M, et al. European Association of Echocardiography recommendations for standardization of performance, digital storage and reporting of echocardiographic studies. Eur J Echocardiogr. 2008;9(4):438-48. 19. Kylhammar D, Kjellstrom B, Hjalmarsson C, Jansson K, Nisell M, Soderberg S, et al. A comprehensive risk stratification at early follow-up determines prognosis in pulmonary arterial hypertension. Eur Heart J. 2017.

20. Boucly A, Weatherald J, Savale L, Jais X, Cottin V, Prevot G, et al. Risk assessment, prognosis and guideline implementation in pulmonary arterial hypertension. Eur Respir J. 2017;50(2). 21. Hoeper MM, Kramer T, Pan Z, Eichstaedt CA, Spiesshoefer J, Benjamin N, et al. Mortality in pulmonary arterial hypertension: prediction by the 2015 European pulmonary hypertension guidelines risk stratification model. Eur Respir J. 2017;50(2).

22. Coghlan JG, Channick R, Chin K, Di Scala L, Galie N, Ghofrani HA, et al. Targeting the Prostacyclin Pathway with Selexipag in Patients with Pulmonary Arterial Hypertension Receiving Double Combination Therapy: Insights from the Randomized Controlled GRIPHON Study. Am J Cardiovasc Drugs. 2018;18(1):37-47.

23. McLaughlin VV, Gaine SP, Howard LS, Leuchte HH, Mathier MA, Mehta S, et al. Treatment goals of pulmonary hypertension. J Am Coll Cardiol. 2013;62(25 Suppl):D73-81.

24. Deboeck G, Scoditti C, Huez S, Vachiery JL, Lamotte M, Sharples L, et al. Exercise testing to predict outcome in idiopathic versus associated pulmonary arterial hypertension. Eur Respir J. 2012;40(6):1410-9.

25. McKenna SP, Doughty N, Meads DM, Doward LC, Pepke-Zaba J. The Cambridge Pulmonary Hypertension Outcome Review (CAMPHOR): a measure of health-related quality of life and quality of life for patients with pulmonary hypertension. Qual Life Res. 2006;15(1):103-15. 
26. Cima K, Twiss J, Speich R, McKenna SP, Grunig E, Kahler CM, et al. The German adaptation of the Cambridge pulmonary hypertension outcome review (CAMPHOR). Health Qual Life Outcomes. 2012;10(1):110.

27. Meads DM, McKenna SP, Doughty N, Das C, Gin-Sing W, Langley J, et al. The responsiveness and validity of the CAMPHOR Utility Index. Eur Respir J. 2008;32(6):1513-9.

28. Brooks R. EuroQol: the current state of play. Health Policy. 1996;37(1):53-72. 
Figure 1: Flow-chart of the patients treated with selexipag as add-on therapy

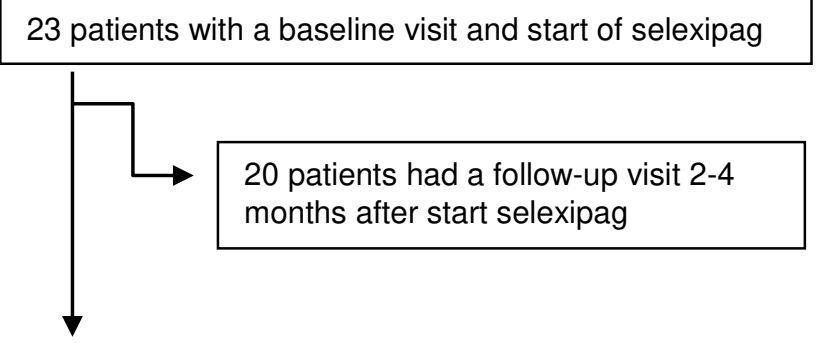

22 patients last visit or last visit before stopping selexipag

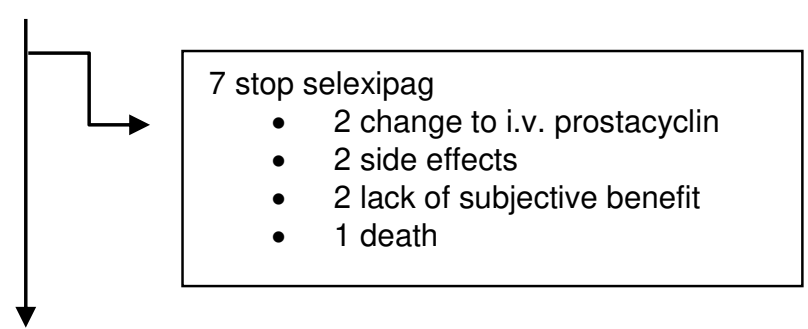

15 patients with ongoing oral triple combination therapy 
Figure 2: NYHA functional class at baseline and at the last visit NYHA functional class

$\mathrm{n}=7$
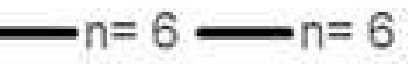

$n=1$

$n=1$

$n=1$

$--\cdot$ median

4

3
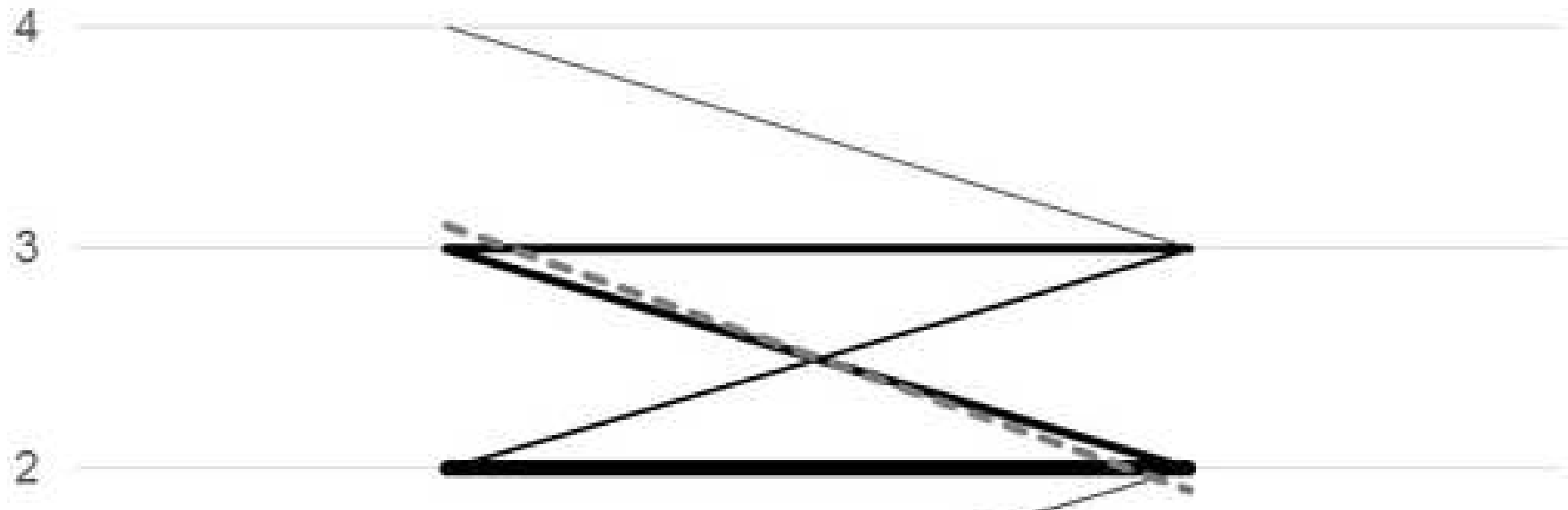

2

1

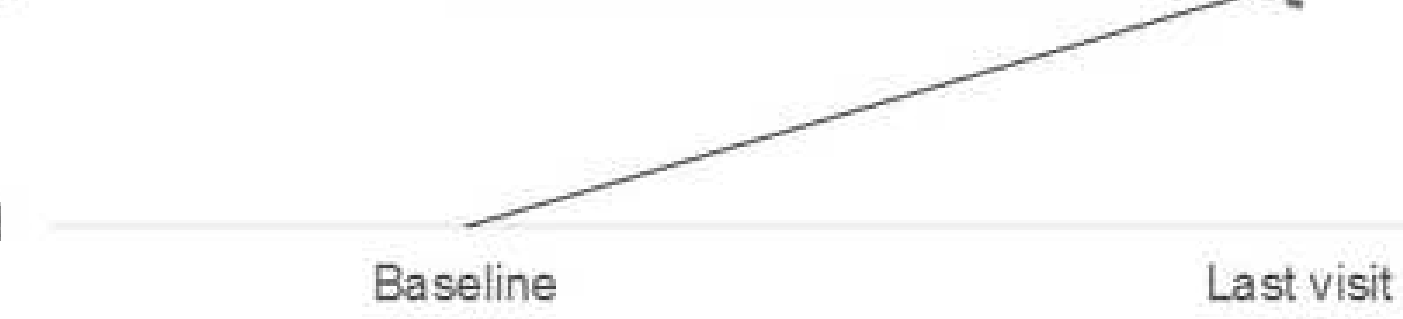

$\mathrm{n}$ represents the number of patients 


\section{Table 1: Patient's baseline characteristics}

\begin{tabular}{|c|c|}
\hline Subjects & 23 \\
\hline Age years & $56(46 ; 66)$ \\
\hline Time from diagnosis to start of selexipag (months) & $24(6 ; 70)$ \\
\hline Female & $14(61 \%)$ \\
\hline Body mass index $(\mathrm{kg} / \mathrm{m} 2)$ & $25.6(23 ; 29)$ \\
\hline PH classification & \\
\hline PAH WHO group 1 & 20 \\
\hline Idiopathic & 14 \\
\hline Associated with congenital heart disease & 3 \\
\hline Associated with connective tissue disease & 2 \\
\hline Associated with schistosomiasis & 1 \\
\hline CTEPH & 3 \\
\hline after endarterectomy & 2 \\
\hline inoperable & 1 \\
\hline NYHA FC & \\
\hline I & 1 \\
\hline II & 8 \\
\hline III & 13 \\
\hline IV & 1 \\
\hline Baseline hemodynamics right heart catheter $n=22$ & \\
\hline Mean pulmonary artery pressure $(\mathrm{mmHg})$ & $48(42 ; 54)$ \\
\hline Right atrium pressure $(\mathrm{mmHg})$ & $8.5(5 ; 13)$ \\
\hline Pulmonary capillary wedge pressure $(\mathrm{mmHg})$ & $11(9 ; 12)$ \\
\hline Pulmonary vascular resistance (WU) & $8(6 ; 10)$ \\
\hline Cardiac output (I/min) & $4.8(4 ; 5.8)$ \\
\hline Cardiac index (l/min/m2) & $2.8(2.4 ; 3.3)$ \\
\hline PAH targeted therapy & \\
\hline Endothelin receptor antagonist & 23 \\
\hline Phosphodiesterase 5 inhibitor & 20 \\
\hline Soluble guanylate cyclase stimulator & 3 \\
\hline Imatinib & 1 \\
\hline Iloprost inhalation & 1 \\
\hline Other therapies & \\
\hline Diuretics & 17 \\
\hline Anticoagulation & 15 \\
\hline Betablocker & 3 \\
\hline ACEI/ATII & 5 \\
\hline Oxygen: only nocturnal / 16-24h/day & $6 / 7$ \\
\hline
\end{tabular}

Values are expressed as median (quartiles) or number (\%).

$\mathrm{PH}$ : pulmonary hypertension, $\mathrm{PAH}$ : pulmonary arterial hypertension, $\mathrm{CTEPH}$ : chronic thromboembolic pulmonary hypertension, NYHA FC: New York heart association functional class, ACEI: angiotensin converting enzyme inhibitor, ATII: angiotensin receptor 2 antagonist. 
Table 2: Baseline data and outcomes at follow-up 2-4 months and at the last visit

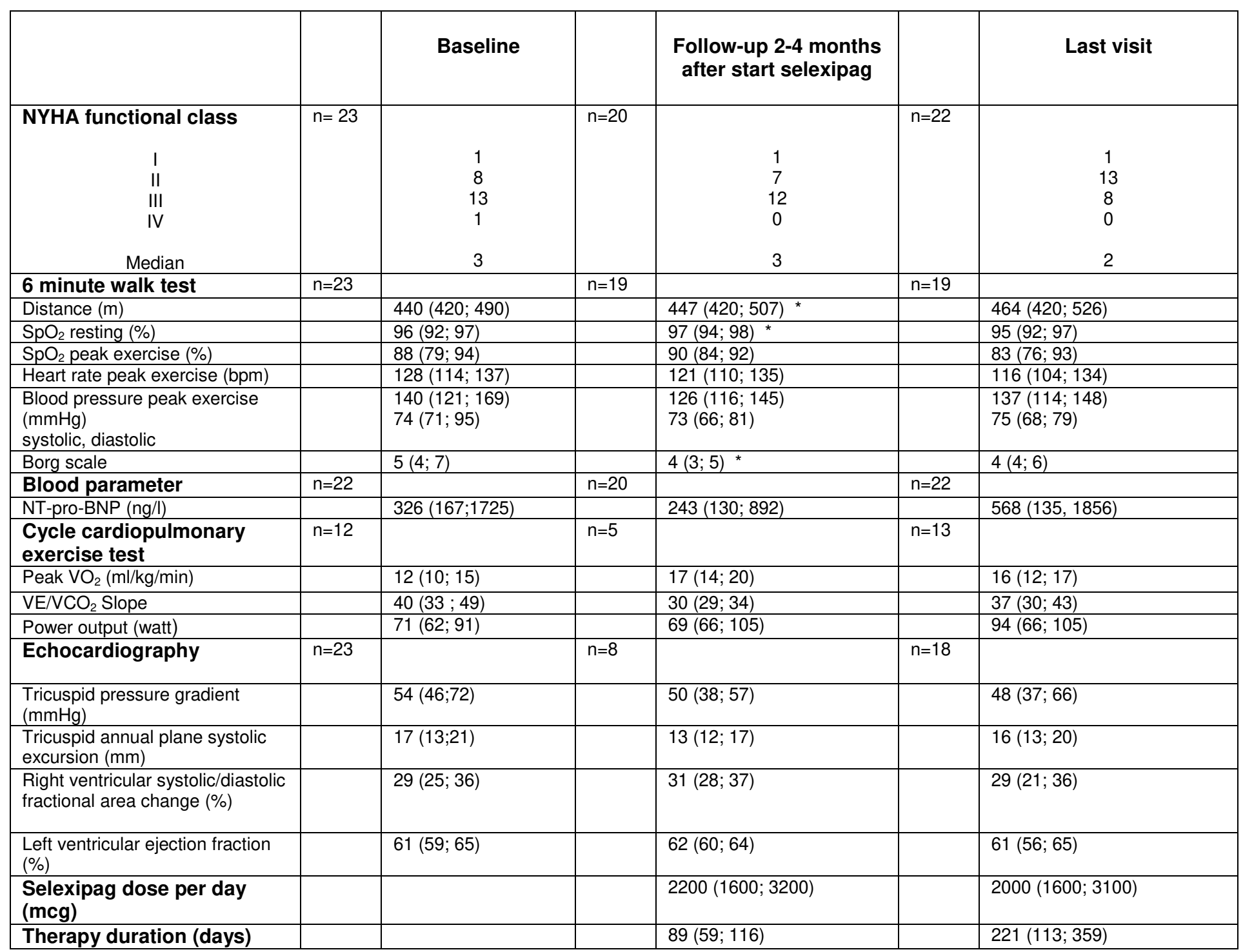

Values are expressed as median (quartiles). $p<0.05$ was considered as statistically significant change from baseline and is marked with *. $\mathrm{SpO}_{2}$ : peripheral oxygen saturation, NT-pro-BNP: N-terminal brain natriuretic peptide, peak $\mathrm{VO}_{2}$ : maximal oxygen uptake. $\mathrm{VE}$ : minute ventilation, $\mathrm{VCO}_{2}$ : carbon dioxide output. 
Table 3: Quality of life at baseline and during therapy with selexipag

\begin{tabular}{|l|c|l|c|l|l|l|}
\hline & $\mathrm{n}$ & Baseline & $\mathrm{n}$ & Follow-up & $\mathrm{p}$-value & Effect size (Cl) \\
\hline CAMPHOR & 14 & & 13 & & & \\
\hline symptoms & & $\mathbf{8}(5 ; 11)$ & & $4(3 ; 8)$ & $\mathbf{0 . 0 1 4}$ & $-0.68(-1.26$ to -0.11$)$ \\
\hline activity & & $9(6 ; 10)$ & & $7(5 ; 9)$ & 0.303 & $-0.36(-1.07$ to 0.35$)$ \\
\hline quality of life & & $3(1 ; 5)$ & & $1(0 ; 2)$ & $\mathbf{0 . 0 4 1}$ & $-0.42(-0.80$ to -0.03$)$ \\
\hline EuroQoL visual analog scale & 14 & $55(43 ; 64)$ & 12 & $65(60 ; 72)$ & $\mathbf{0 . 0 3 9}$ & $0.65(0.09$ to 1.21$)$ \\
\hline Self reported therapeutic effect & 11 & $2(2 ; 3)$ & 11 & $1(1 ; 2)$ & $\mathbf{0 . 0 4 6}$ & $-1.26(-2.38$ to -0.13$)$ \\
\hline Self reported health status & 11 & $4(3 ; 4)$ & 11 & $3(3 ; 4)$ & 0.317 & $-0.49(-1.65$ to 0.67$)$ \\
\hline $\begin{array}{l}\text { Minnesota living with heart } \\
\text { failure questionnaire }\end{array}$ & 14 & & 11 & & & \\
\hline general score & & $22(9 ; 43)$ & & $23(17 ; 31)$ & 0.45 & $-0.27(-0.86$ to 0.32$)$ \\
\hline physical & & $12(7 ; 20)$ & & $11(9 ; 15)$ & 0.44 & $-0.34(-0.95$ to 0.26$)$ \\
\hline emotional & & $4(1 ; 11)$ & & $3(2 ; 7)$ & 0.26 & $-0.36(-1.01$ to 0.29$)$ \\
\hline
\end{tabular}

Values are expressed as median (quartiles). $\mathrm{Cl}$ : 95\% confidence interval. P-values by Wilcoxon matched pair test from baseline to follow-up are shown. CAMPHOR: Cambridge Pulmonary Hypertension Outcome Review. CAMPHOR, self-reported therapeutic effect, self-reported health status and Minnesota living with heart failure questionnaire: a lower score indicates a better status. EuroQoL: a higher score indicates a better quality of life. Effect size is calculated as mean change during follow-up divided by the pooled standard deviation (Cohen's d). 


\section{Table 1: Patient's baseline characteristics}

\begin{tabular}{|c|c|}
\hline Subjects & 23 \\
\hline Age years & $56(46 ; 66)$ \\
\hline Time from diagnosis to start of selexipag (months) & $24(6 ; 70)$ \\
\hline Female & $14(61 \%)$ \\
\hline Body mass index $(\mathrm{kg} / \mathrm{m} 2)$ & $25.6(23 ; 29)$ \\
\hline PH classification & \\
\hline PAH WHO group 1 & 20 \\
\hline Idiopathic & 14 \\
\hline Associated with congenital heart disease & 3 \\
\hline Associated with connective tissue disease & 2 \\
\hline Associated with schistosomiasis & 1 \\
\hline CTEPH & 3 \\
\hline after endarterectomy & 2 \\
\hline inoperable & 1 \\
\hline NYHA FC & \\
\hline I & 1 \\
\hline II & 8 \\
\hline III & 13 \\
\hline IV & 1 \\
\hline Baseline hemodynamics right heart catheter $n=22$ & \\
\hline Mean pulmonary artery pressure $(\mathrm{mmHg})$ & $48(42 ; 54)$ \\
\hline Right atrium pressure $(\mathrm{mmHg})$ & $8.5(5 ; 13)$ \\
\hline Pulmonary capillary wedge pressure $(\mathrm{mmHg})$ & $11(9 ; 12)$ \\
\hline Pulmonary vascular resistance (WU) & $8(6 ; 10)$ \\
\hline Cardiac output (I/min) & $4.8(4 ; 5.8)$ \\
\hline Cardiac index (l/min/m2) & $2.8(2.4 ; 3.3)$ \\
\hline PAH targeted therapy & \\
\hline Endothelin receptor antagonist & 23 \\
\hline Phosphodiesterase 5 inhibitor & 20 \\
\hline Soluble guanylate cyclase stimulator & 3 \\
\hline Imatinib & 1 \\
\hline Iloprost inhalation & 1 \\
\hline Other therapies & \\
\hline Diuretics & 17 \\
\hline Anticoagulation & 15 \\
\hline Betablocker & 3 \\
\hline ACEI/ATII & 5 \\
\hline Oxygen: only nocturnal / 16-24h/day & $6 / 7$ \\
\hline
\end{tabular}

Values are expressed as median (quartiles) or number (\%).

$\mathrm{PH}$ : pulmonary hypertension, $\mathrm{PAH}$ : pulmonary arterial hypertension, $\mathrm{CTEPH}$ : chronic thromboembolic pulmonary hypertension, NYHA FC: New York heart association functional class, ACEI: angiotensin converting enzyme inhibitor, ATII: angiotensin receptor 2 antagonist. 
Table 2: Baseline data and outcomes at follow-up 2-4 months and at the last visit

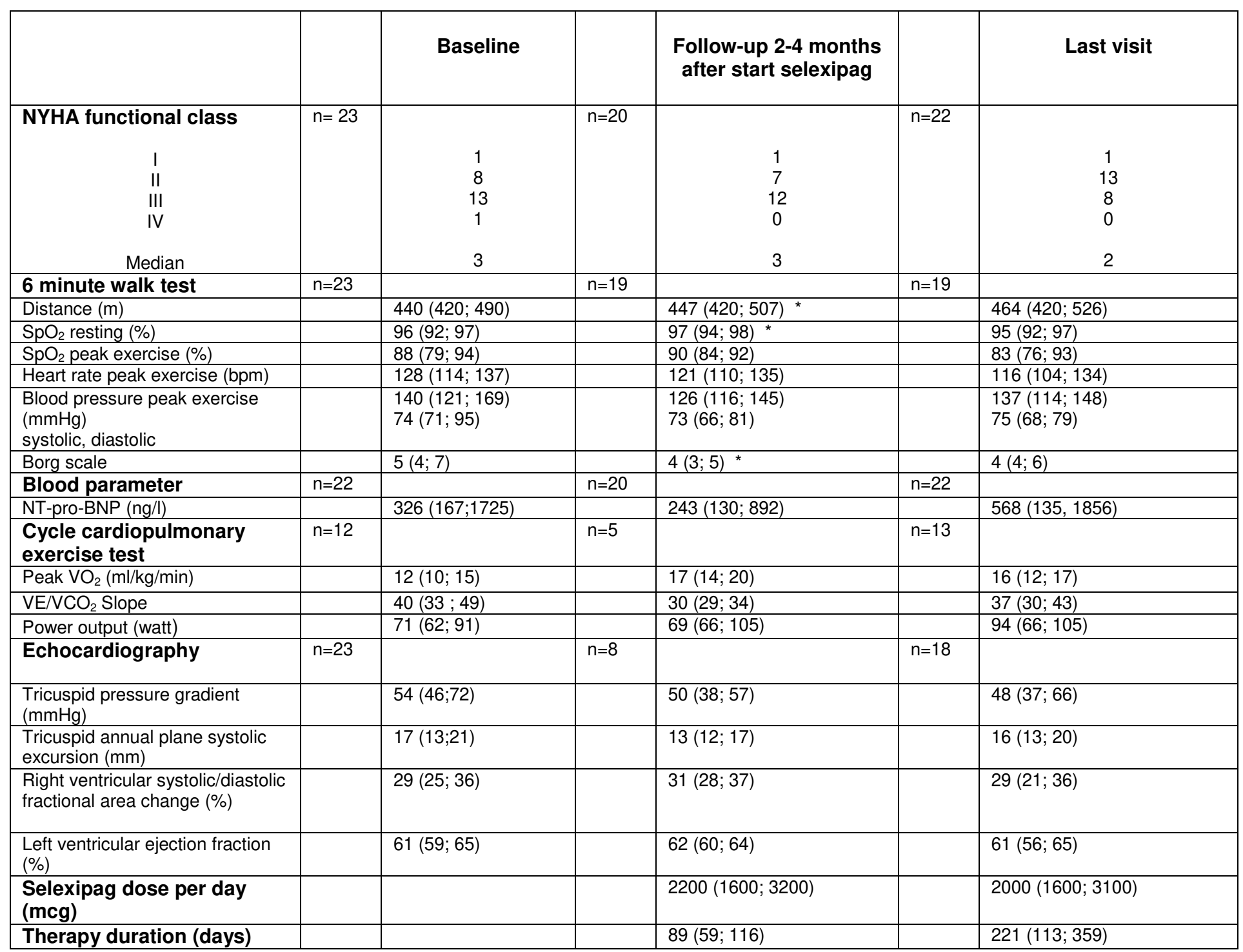

Values are expressed as median (quartiles). $p<0.05$ was considered as statistically significant change from baseline and is marked with *. $\mathrm{SpO}_{2}$ : peripheral oxygen saturation, NT-pro-BNP: N-terminal brain natriuretic peptide, peak $\mathrm{VO}_{2}$ : maximal oxygen uptake. $\mathrm{VE}$ : minute ventilation, $\mathrm{VCO}_{2}$ : carbon dioxide output. 
Table 3: Quality of life at baseline and during therapy with selexipag

\begin{tabular}{|l|c|l|c|l|l|l|}
\hline & $\mathrm{n}$ & Baseline & $\mathrm{n}$ & Follow-up & $\mathrm{p}$-value & Effect size (Cl) \\
\hline CAMPHOR & 14 & & 13 & & & \\
\hline symptoms & & $8(5 ; 11)$ & & $4(3 ; 8)$ & $\mathbf{0 . 0 1 4}$ & $-0.68(-1.26$ to -0.11$)$ \\
\hline activity & & $9(6 ; 10)$ & & $7(5 ; 9)$ & 0.303 & $-0.36(-1.07$ to 0.35$)$ \\
\hline quality of life & & $\mathbf{3}(1 ; 5)$ & & $1(0 ; 2)$ & $\mathbf{0 . 0 4 1}$ & $-0.42(-0.80$ to -0.03$)$ \\
\hline EuroQoL visual analog scale & 14 & $55(43 ; 64)$ & 12 & $65(60 ; 72)$ & $\mathbf{0 . 0 3 9}$ & $0.65(0.09$ to 1.21$)$ \\
\hline Self reported therapeutic effect & 11 & $2(2 ; 3)$ & 11 & $1(1 ; 2)$ & $\mathbf{0 . 0 4 6}$ & $-1.26(-2.38$ to -0.13$)$ \\
\hline Self reported health status & 11 & $4(3 ; 4)$ & 11 & $3(3 ; 4)$ & 0.317 & $-0.49(-1.65$ to 0.67$)$ \\
\hline $\begin{array}{l}\text { Minnesota living with heart } \\
\text { failure questionnaire }\end{array}$ & 14 & & 11 & & & \\
\hline general score & & $22(9 ; 43)$ & & $23(17 ; 31)$ & 0.45 & $-0.27(-0.86$ to 0.32$)$ \\
\hline physical & & $12(7 ; 20)$ & & $11(9 ; 15)$ & 0.44 & $-0.34(-0.95$ to 0.26$)$ \\
\hline emotional & & $4(1 ; 11)$ & & $3(2 ; 7)$ & 0.26 & $-0.36(-1.01$ to 0.29$)$ \\
\hline
\end{tabular}

Values are expressed as median (quartiles). $\mathrm{Cl}$ : $95 \%$ confidence interval. P-values by Wilcoxon matched pair test from baseline to follow-up are shown. CAMPHOR: Cambridge Pulmonary Hypertension Outcome Review. CAMPHOR, self-reported therapeutic effect, self-reported health status and Minnesota living with heart failure questionnaire: a lower score indicates a better status. EuroQoL: a higher score indicates a better quality of life. Effect size is calculated as mean change during follow-up divided by the pooled standard deviation (Cohen's d). 